\title{
Correction to: Virtual element method (VEM)-based topology optimization: an integrated framework
}

\author{
Heng $\mathrm{Chi}^{1}$ • Anderson Pereira ${ }^{2}$ - Ivan F. M. Menezes ${ }^{2} \cdot$ Glaucio H. Paulino $^{1}$ \\ Published online: 9 July 2020 \\ (C) Springer-Verlag GmbH Germany, part of Springer Nature 2020
}

\section{Correction to: Structural and Multidisciplinary Optimization https://doi.org/10.1007/s00158-019-02268-w}

The original version of this article unfortunately contains several errors introduced by the typesetter during the publishing process and which have been corrected.

Publisher's note Springer Nature remains neutral with regard to jurisdictional claims in published maps and institutional affiliations.

The online version of the original article can be found at https://doi.org/ 10.1007/s00158-019-02268-w

Glaucio H. Paulino

paulino@gatech.edu

Heng Chi

hchi6@gatech.edu

Anderson Pereira

anderson@puc-rio.br

Ivan F. M. Menezes

ivan@puc-rio.br

1 School of Civil and Environmental Engineering, Georgia Institute of Technology, 790 Atlantic Drive, Atlanta, GA 30332, USA

2 Pontifical Catholic University of Rio de Janeiro (PUC-Rio), Rua Marquês de São Vicente, 225, Rio de Janeiro, R.J. 22451-900, Brazil 